\title{
FASCIATION IN MAIZE KERNELS ${ }^{1}$
}

\author{
T. K. WOLFE
}

\section{Virginta Agricultural Experiment Station}

IN the summer of 1914 a number of different varieties of corn were crossed for the purpose of studying the effect of hybridization on the weight of hybrid and pure seed produced. One of the crosses made was between Improved Leaming as the seed parent and Boone County Special as the pollen parent, the pollen of the two varieties being mixed and applied to the same ear. The former variety is a yellow dent and the latter a white dent. On this ear was found two kernels, each of which had two embryos. The description of the kernels and their progeny will be given in this paper.

\section{Description of Kernels}

In corn, the embryo is normally on the side of the kernel toward the tip of the ear. These kernels had an embryo on both sides. The kernels seemed to be normal with the exception of the extra embryo and a slight prominence or line of demarkation which extended around each kernel parallel to the embryos.

Kernel No. 1 was yellow in one half, while the other half was a paler yellow (diluted with white). Kernel No. 2 was yellow in both halves. Although there was a variation in the degree of color, the results of the $F_{1}$ generation proved that both halves of each kernel were hybrid.

\section{Progeny from Kernels}

The kernels were planted in pots in the greenhouse in April in greenhouse soil and in due time each kernel pro-

1 Paper 2 from department of agronomy, Virginia Agricultural Experiment Station, Blacksburg, Virginia. 


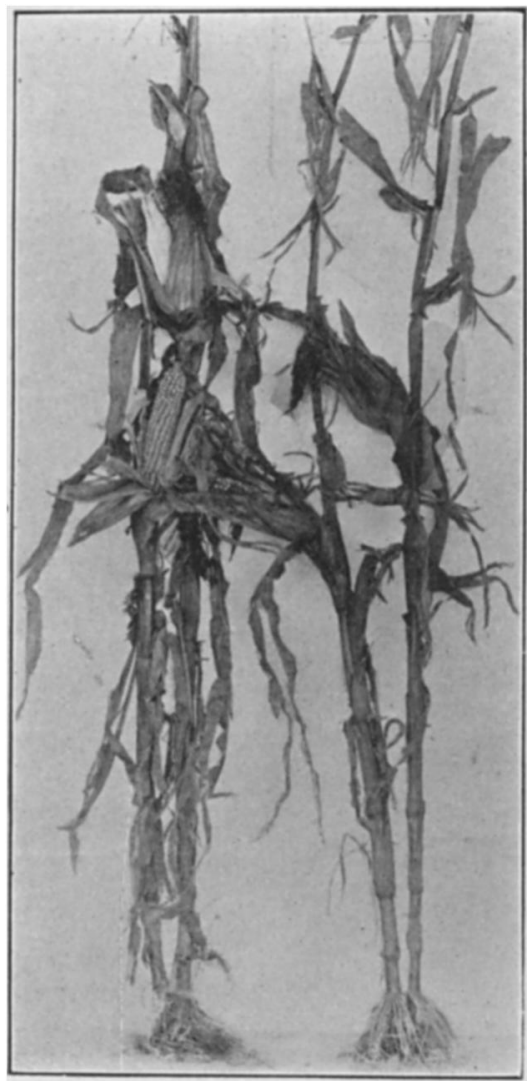

FIG. 1. F' generation progeny of fasciated kernels. Stalks on the left, progeny of kernel No. 2, those on the right, progeny of kernel No. 1. (About one fifteenth natural size.)

At first the tassels and silks were bagged to prevent foreign pollination. All the pistillate flowers were selfpollinated, the pollen being applied by hand at this time. Later, paper tubes were fastened to the tassel and carried to the uppermost ear shoot, the lower ear duced two stalks. In May, after danger of frost was over, the contents of each pot were removed from the greenhouse and placed in the field. The time of tasseling and silking and other data were recorded during the season as shown in Table I. Each stalk produced two ear shoots; however, only one ear shoot on each stalk produced an ear.

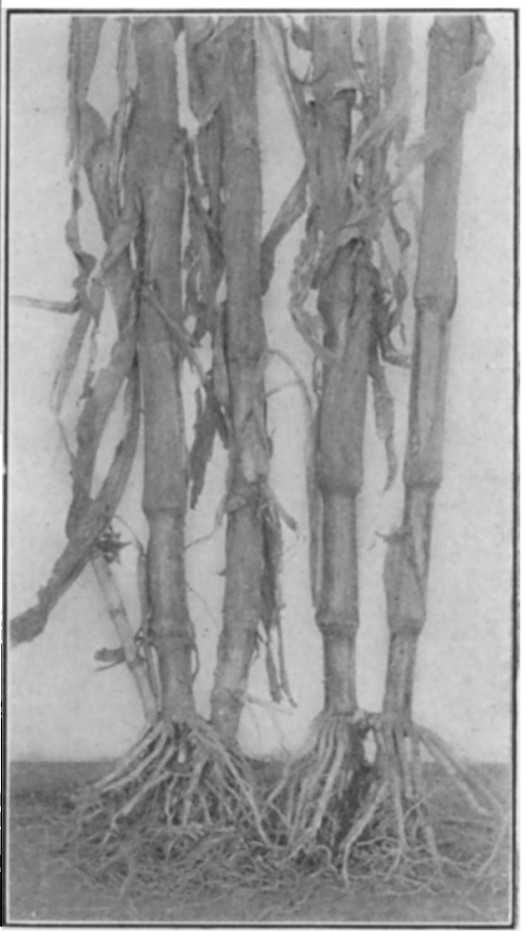

FIG. 2. $F_{1}$ generation progeny from fasciated kernel No. 2 on the left, and fasciated kernel No. 1 on the right, showing root systems. (About one fifth natural size.) 
shoots being covered with bags and hand pollinated as was done at first.

\section{Description of $\mathrm{F}_{1}$ Generation Stalks}

After the total growth had been made, data were recorded as to the height and diameter of stalks, length, width, and number of leaves, while the dates of tasseling and silking had been obtained previously.

Fig. 1 shows picture of entire stalks after harvesting.

TABLE I

Height and Diameter of Stalks, Length and Width of Leaves, in Inches. Number of Leaves and Dates of Tasseling and Silking of $F_{1}$ Generation Stalks from Fasciated Kernels of Maize

\begin{tabular}{|c|c|c|c|c|c|c|c|c|c|c|}
\hline \multirow{3}{*}{$\begin{array}{c}\text { Kernel } \\
\text { No. }\end{array}$} & \multirow{3}{*}{$\begin{array}{l}\text { Stalk } \\
\text { No. }\end{array}$} & \multirow{3}{*}{$\begin{array}{c}\text { Number } \\
\text { of } \\
\text { Leaves }\end{array}$} & \multirow{3}{*}{$\begin{array}{c}\text { Height } \\
\text { of } \\
\text { Stalks }\end{array}$} & \multirow{2}{*}{\multicolumn{2}{|c|}{ Length of Leaves }} & \multirow{2}{*}{\multicolumn{2}{|c|}{ Width of Leaves }} & \multirow{3}{*}{$\begin{array}{l}\text { Diameter } \\
\text { of Stalk }\end{array}$} & \multicolumn{2}{|c|}{ Date of } \\
\hline & & & & & & & & & Tassel- & Silk- \\
\hline & & & & 8 th & 9 th & 8 th & 9 th & & & \\
\hline \multirow[t]{2}{*}{1} & 1 & 11 & 99 & $33 \frac{1}{4}$ & $31 \frac{7}{8}$ & $3 \frac{15}{16}$ & $3 \frac{13}{16}$ & $\frac{11}{16}$ & 12 & 26 \\
\hline & 2 & 13 & 102 & $36 \frac{1}{8}$ & $33 \frac{1}{2}$ & $4 \frac{1}{16}$ & $3 \frac{3}{4}$ & & 16 & 24 \\
\hline \multirow[t]{2}{*}{2} & 3 & 14 & $92 \frac{1}{4}$ & $36 \frac{3}{4}$ & $34 \frac{5}{8}$ & $4 \frac{11}{16}$ & $4 \frac{5}{8}$ & $1 \frac{1}{8}$ & 12 & 19 \\
\hline & 4 & 14 & $108 \frac{3}{4}$ & $40 \frac{1}{8}$ & $37 \frac{5}{8}$ & $4 \frac{1}{16}$ & $4 \frac{3}{16}$ & $\frac{7}{8}$ & 14 & 21 \\
\hline
\end{tabular}

At maturity, the entire plants were removed from the ground in such a way as to retain as many of the roots as possible. The soil was removed and a photograph was taken of the roots (Fig. 2) to especially emphasize the fact that each stalk was separate and distinct from the other and could not be classed as a tiller from the other stalk, although both were united at the radicle.

\section{Description of $\mathrm{F}_{1}$ Generation Kernels}

Fig. 3 is a photograph of the four ears produced. All of them show Mendelian splitting. The number and ratio of yellow and white kernels will be given in Table II. None of the kernels possessed two embryos like their parents. 


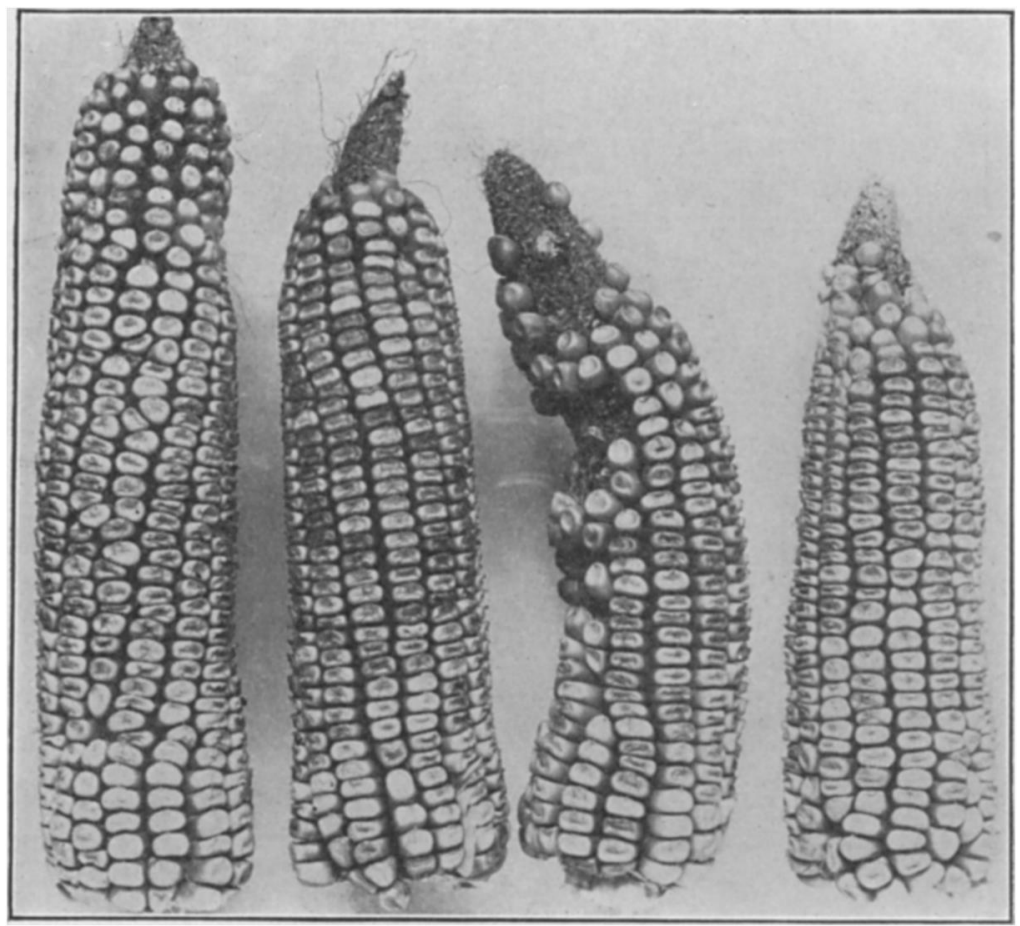

Frg. 3. $F_{1}$ generation ears produced by the fasciated kernels. Beginning at the left, the first and second ears were produced by kernel No. 2 ; stalks numbers 1 and 2, respectively. The third and fourth ears were produced by kernel No. 1 ; stalks 3 and 4 , respectively. (About one half natural size.)

\section{TABLE II}

Number and Ratio of White and Yellow Kernels in the F $_{1}$ Generation

\begin{tabular}{c|c|c|c|c|c}
\hline \hline $\begin{array}{c}\text { Kernel } \\
\text { No. }\end{array}$ & $\begin{array}{c}\text { Stalk } \\
\text { No. }\end{array}$ & $\begin{array}{c}\text { Ear } \\
\text { No. }\end{array}$ & $\begin{array}{c}\text { Number Yellow } \\
\text { Kernels }\end{array}$ & $\begin{array}{c}\text { Number White } \\
\text { Kernels }\end{array}$ & $\begin{array}{c}\text { Ratio of Yellow to White } \\
\text { Kernels }\end{array}$ \\
\cline { 1 - 3 } 1 & 1 & 1 & 218 & 76 & $2.86: 1$ \\
& 2 & 2 & 377 & 60 & $6.28: 1$ \\
2 & 3 & 3 & 393 & 182 & $2.15: 1$ \\
& 4 & 4 & 408 & 130 & $\begin{array}{c}3.14: 1 \\
\text { Average ratio, 3.61:1 }\end{array}$ \\
\hline
\end{tabular}

This generation seed will be grown next season in order to discover whether any fasciated kernels appear. After these results are obtained, a discussion of the kernels reported in this paper will be presented. 